\title{
Acute maxillary sinusitis detected by bedside emergency department ultrasonography
}

\author{
Firat Bektas • Secgin Soyuncu $\cdot$ Ozlem Yigit
}

Received: 18 December 2009 / Accepted: 13 June 2010 /Published online: 21 August 2010

(C) Springer-Verlag London Ltd 2010

Bedside emergency department (ED) ultrasound (US) provides critical information to clinicians by noninvasively, rapidly determining various anatomical structures [1]. The sonographic diagnosis of acute sinusitis (AS) has been studied, and a wide range of sensitivities and specificities for the diagnosis of AS by US has been reported $[2,3]$. The authors present a case of sinusitis diagnosed by US in the ED.

A 32-year-old woman presented to the ED with a history of fever, sore throat and nasal obstruction of 5-day duration. She denied any cough, fullness of face or

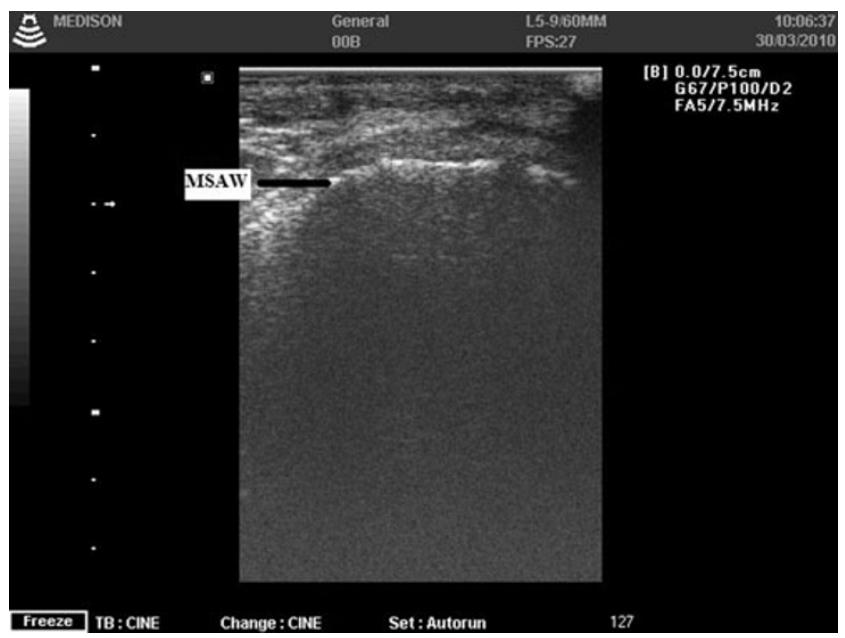

Fig. 1 Ultrasonographic examination of the normal maxillary sinus

This study was supported by the Akdeniz University Research Foundation.

F. Bektas $(\bowtie) \cdot$ S. Soyuncu $\cdot$ O. Yigit

Department of Emergency Medicine,

Akdeniz University Faculty of Medicine,

07059 Antalya, Turkey

e-mail: fbektas@akdeniz.edu.tr

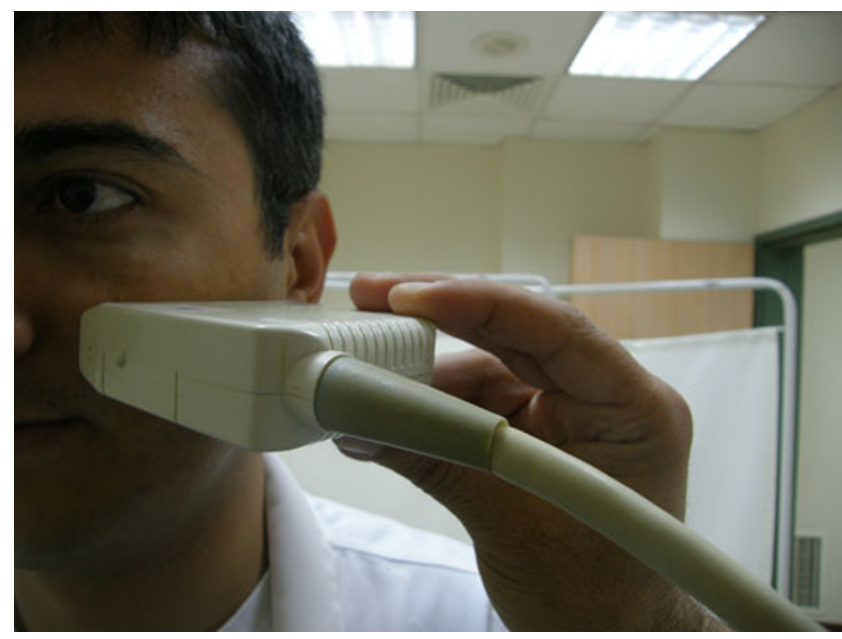

Fig. 2 Revonta's technique: while the patient was in the sitting position. The patient's head was in slight flexion so that an imaginary line from the auditory canal to the lower margin of the orbit was horizontal

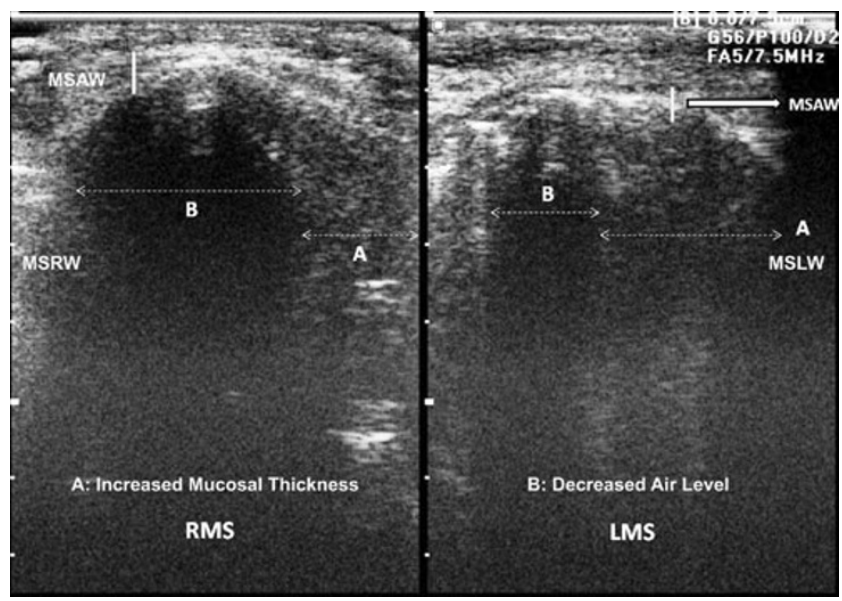

Fig. 3 Ultrasonographic examination of the acute maxillary sinusitis. a Mucosal thickness; b air level of the sinus. RMS: right maxillary sinus, LMS: left maxillary sinus, MSAW: maxillary sinus anterior wall 


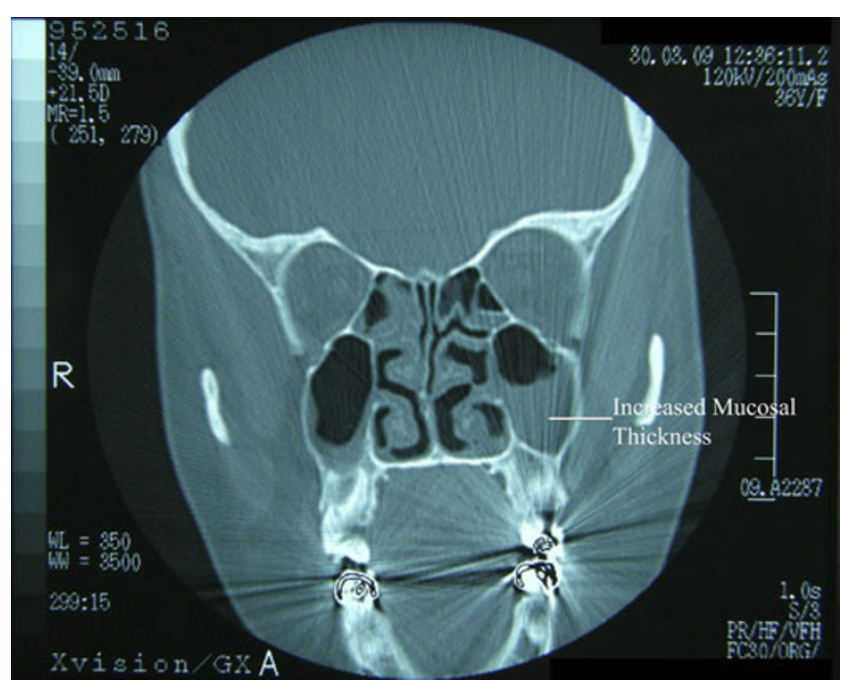

Fig. 4 Paranasal computed tomography showed bilateral acute maxillary sinusitis

headache. The vital signs of the patient were normal except for fever of $38.6^{\circ} \mathrm{C}$. Physical examination was normal except for pharyngeal erythema. Since there was a nasal obstruction in her history, this finding led us to think that the patient might have an acute sinusitis (AS). In order to strengthen our diagnosis, we decided to perform an US examination since it is an easily performed, rapid, cheap, noninvasive and non-ionizing method. Figure 1 demonstrates a normal maxillary sinus. Bedside US examination was performed according to the method described by Revonta (Fig. 2) [4]. An increase in mucosal thickness and decrease of aeration in both of the maxillary sinuses were shown both with bedside US (Fig. 3) and paranasal sinus tomography (Fig. 4). The patient was discharged from the ED with antibiotics, oral paracetamol tablets and a nasal decongestant.

US, while operator dependent, can be a useful tool to reduce the number of unnecessary tests ordered and thus aid in a rapid diagnosis and therapeutic interventions.

\section{References}

1. American College of Emergency Physicians (2006) Emergency ultrasound imaging criteria compendium. Ann Emerg Med 48:487510

2. Hilbert G, Vargas F, Valentino R, Gruson D, Chene G, Bébéar C, Gbikpi-Benissan G, Cardinaud JP (2001) Comparison of B-mode ultrasound and computed tomography in the diagnosis of maxillary sinusitis in mechanically ventilated patients. Crit Care Med 29 (7):1337-1342

3. Lichtenstein D, Biderman P, Mezière G, Gepner A (1998) The "sinusogram", a real-time ultrasound sign of maxillary sinusitis. Intensive Care Med 24(10):1057-1061

4. Revonta M (1980) Ultrasound in the diagnosis of maxillary and frontal sinusitis. Acta Otolaryngol Suppl 370:1-55 